\title{
Lately Performed Arterial Switch Operation in a Three Years Old Child Diagnosed of Transposition of Great Arteries
}

\author{
Huseyin Avni Solgun, ${ }^{1 *}$ Farid Gojayev ${ }^{2}$ \\ ${ }^{1}$ Department of Pediatric Hematology and Oncology, Health Science University Basaksehir Cam and Sakura City Hospital, Turkey \\ ${ }^{2}$ Department of Pediatric Cardiovasculer Surgery, Medical Park Bahcelievler Hospital, Turkey
}

\begin{abstract}
Bacground: Insidans for transposition of great arterieas(TGA) is \%0.5-1 of all congential hearth diseases. There is reverse output of aorta and pulmonary arteries in hearth ventricules. Additionally there is ventriculer septal defect(VSD) in $\% 25$ of TGA patients. In some infants there can be either left ventriculer outflow tract stenosis. Arterial switch (Jaten) operation is current accepted procedure for TGA treatment.

Case presentation: The Patient with the symptom of severe syanosis from birth have been diagnosed as TGA, VSD and ASD with pediatric cardiology examination in an extarnal hospital. After a withut follow-up period; when 34 months age the patient applicated to our institute hospital by the complains of severe synosis and reduction of effort capacity. According to ecocardiography and angiograghy findings, Arterial switch operation(AS) planned and performed even late age of patient.
\end{abstract}

Conclusion: Generally; AS in TGA patients is prefered to be done in the first month of life. In literature there is very rare cases presented in early childhood patients. In respect to this knowledge we presented a succesful atrial switch operation in three years old patient.

Keywords: arterial switch(Jaten) operation, transposition of great arterieas (TGA)

\section{Introduction}

In TGA patients circulating blood have to be mixed in hearth or anywhere else to continue of life before total correcting operation. Mixing of blood is critical for life maintenance. VSD, atrial septal defect (ASD) or patent ductus arteriosus(PDA) is very important to let this mixing by natural way in this patients. If this event of mixing is not possible by these natural ways an emergency catheterization or atrial septostomy (AS) is necessary to perform. ${ }^{1}$ Generally neonatal first 3 weeks is prefered for AS operation. When this duration delayed mostly AS operation is not possible to perform. To perform delayed correction, firstly palyatif cardiac surgical prosedures is needed to do. ${ }^{2}$ We presented a 3 years of child with diagnosis of
TGA accompanying VSD and ASD in which previously pulmonary bunding operation have been performed.

\section{Case report}

The Patient with the symptom of severe syanosis from birth have been diagnosed as TGA, VSD and ASD via pediatric cardiology examination in an extarnal hospital. Medical treatment managed till 8 months age and afterward the patient refered to our institute hospital and palliative surgery have been planned. Pulmonary bunding and surgical operation have been performed and the patient excharged. When 34 months age the patient applicated to our

\begin{tabular}{l|l}
\hline Quick Response Code: & $\begin{array}{l}\text { \%Corresponding author: Huseyin Avni Solgun, Department of Pediatric Hematology and On- } \\
\text { cology, Health Science University Basaksehir Cam and Sakura City Hospital, Istanbul, Turkey } \\
\text { Received: } 13 \text { October, } 2020 \\
\text { Citation: Huseyin AS, Farid G. Lately Performed Arterial Switch Operation in a Three Years }\end{array}$ \\
Old Child Diagnosed of Transposition of Great Arteries. SOJ Pedia Clin Neonato. 2020;1(1):1- \\
3. DOI: 10.53902/SOJPCN.2020.01.000502
\end{tabular}


institute hospital by the complains of severe synosis and reduction of effort capacity. An echocardiography and angiography have been performed. Pulmonary gradient was $68 \mathrm{mmHg}$ (Figure 1). Atrioventriculer relation was conformable, hearth blanks were normal and ventriculer contractions were normal. There was no ventriculer wall hypoplasia. The valvuler morphology was normal. In angiography no coranary abnormalitiy have been detected. ${ }^{3}$ There was no pulmonary hypertension in pulmunary catheterization (Figure 2).

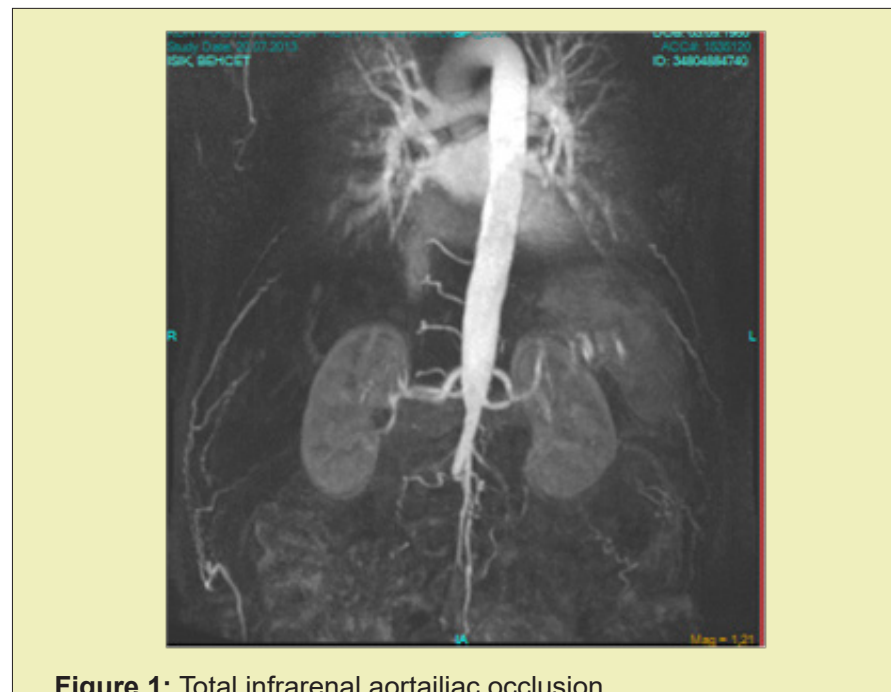

Figure 1: Total infrarenal aortailiac occlusion.

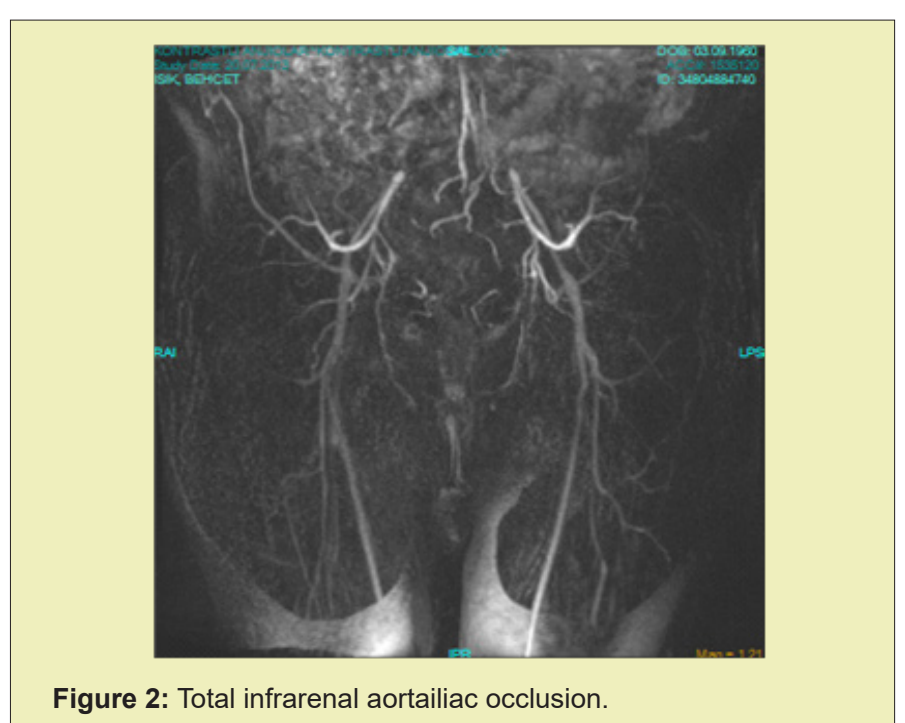

AS have been planned to patient.Cardiopulmonary bypass(CPB) have been performed in 32 degree celcius. During cooling period of CPB, right and left pulmonary arterias have been canalized to hilus antrance and patent ductus arteriosus have been divized. Blood cardioplegia have been used via antegrad way to protect myocardial tissue. Pulmonary arteria debunding, arteriotomy and supravalvuler fibrousus membran resection have been performed respectively.VSD have been fixed via right arteriotomy and patch with continue suture tecnic.Valvuler dilation have been made via 17 number spark plug. After the dilation valvuler leakage has been tested and no valvuler insufficiency has been detected. AS have been performed via Lecomte maneuver. Second cardioplegia dos- age have been given after neoaorta and coranary arterial anastomosis have been performed. Before neopulmunary anastomosis have been performed; leakage of anastomosis, fullness and positions of coranary arterias have been obseverved (Figure 3). Perfusion sufficiency has been tested via observetion of cardioplegia origining from coranary sinus.After neoaorta and coranary anastomosis have been perforemed, bovine patch reconstruction of distal neopulmunary arteria have been performed. Figure 4 Aort clemp have been opened after completion of distal anastomosis. Neopulmonary anastomosis have been performed via $7 / 0$ prolen suture while hearth functions turned back. ASD have been fixed via wide bovine patch. A small openness have been left to continue patent foramen ovale(PFO) mecanism. Atrium have been re-closed and inotropic agents dopamine and adrenaline continue infusion have been initiated intravenoususly. Operation have been completed after sternum have been re-closed. Aortic cross clamp duration was 62 minutes and CPB duration was 112 minutes respectively. In post poertive follow-ups inotropic dopamine and milrinone have been continued and 5 hours later extubation have been done. In subsequent follow-ups, the inotropic treatment was gradually discontinued by moniterizing the patient. Sinus rhythm has been observed in cardiac monitirization and ventricular functions were sufficient in echocardiography.

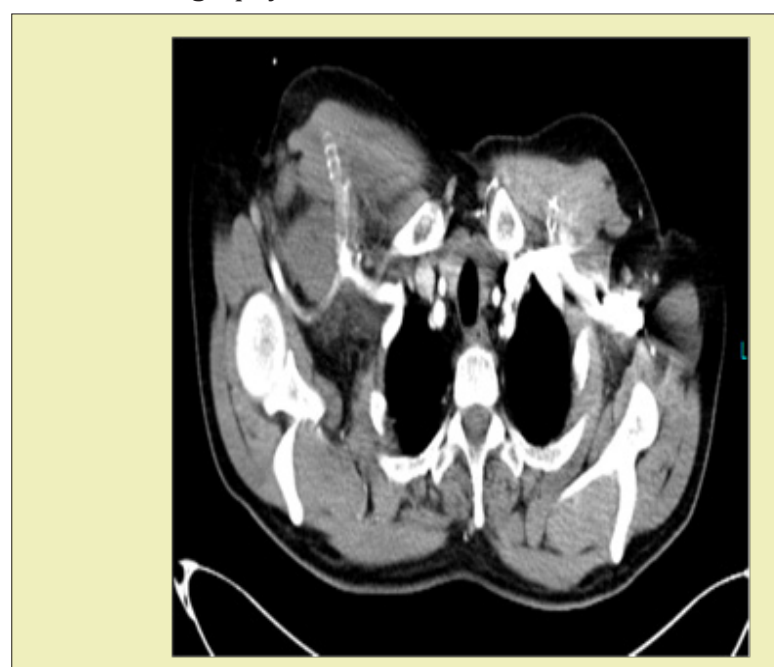

Figure 3: Laseration and hemetoma of graft in anastomosis line.

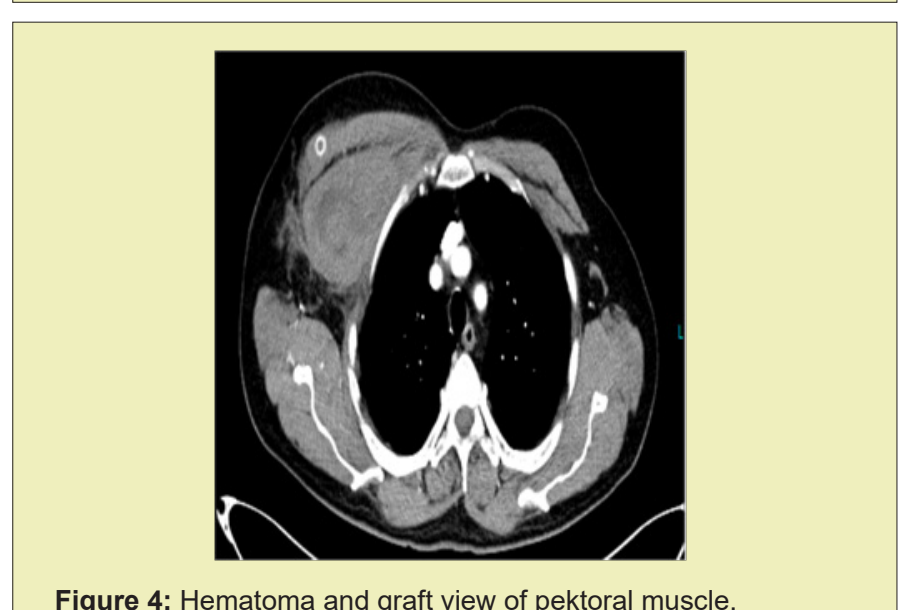

Figure 4: Hematoma and graft view of pektoral muscle. 


\section{Discussion}

In TGA treatment; firstly Senning and Mustard modifications have been performed in 1959 and 1963 respectevily. Various complications have been restricted to use of these modifications. Currently Jaten operations is the main suggestions in this patients. Arterial switch operation is globally prefered method for total anatomical correction of TGA and firstly have been performed by Jaten and et al. In 1975 and have been modified by Lecompte. If the patological status is not consists to perform AS operation; pulmonary bunding,Rastelli operation,atrial switch,Damus-Stansel-Key,Nikaidoh operations can be preferred. ${ }^{4,5}$ Survivallance is not much then 1 year if the surgical treatment have not been performed. Left ventriculer pressure and contraction is the main factor for succes of the basic TGA with intact ventriculer septum. Physciologically pulmonary vascular resistans (PVR) is high in first 2 weeks of life so left ventriculer functions remains normal.After 15 day of life PVR will lower and left ventriuler function will be against low pressure. In time left ventriculer function will become insufficient. ${ }^{6,7}$ Therefore in treatment delayed patients left ventriculer function will be against high systemic vasculer resistans so the cardiac output will become lower and inotropic agents can be needed. In literature the operation is suggested if left vetricüler stroke volume and wall tickness is normal and left/right pressure ratio is higher then 0.70 . In devoloped countries delayed cases are rare but in devoloping countries its more frequent because of several reasons. The cases delayed newborn period like in case to perform atrial switch operation; pulmonary banding and shunt is recommended firstly. This prosudure provides a better left ventriuler afterload performance to prepare patient to AS operation. The time for better left ventriuler performance is reversely related with age of patient.Until 3 months age if palliative pulmonary banding have been performed 3 weeks will be enough even in older childeren this will be more. In devoloped countries recently under 3 months of age the operation is directly recommended as a consensus. In childhood; pulmonary hypertension is also an other factor related with morbidity and mortality of complex TGA patients. ${ }^{8,9}$

\section{Conclusion}

We present a 34 months of age patient with diagnosis of TGA to whom we have performed AS operation successfully. In TGA patients if in early newborn period palliative operation have been performed, left ventriculer functions and diameter is normal; pulmonary hypertension has not been devoloped and coranary arteries are normal in angiography; AS operation is suggestable even in 3 years old patients according to our successful outcome in our case. In literature there is not much knowledge regarding this issue so we emphasize with our case.

\section{References}

1. Miyazaki T, Kado H. Transposition of the great arteries. Kyobu Geka. 2004;57(8): 711-6

2. Wojtalik M, Sharma G, Mrowczynski W, et al. Arterial switch operation in neonates with complex congenital heart defects. Asian Cardiovasc Thorac Ann. 2003;11(1): 14-7.

3. Sung SC, Chang YH, Lee S, et al. Arterial switch operation for transposition of the great arteries with coronary arteries from a single aortic sinus. Ann Thorac Surg. 2005;80(2): 636-41.

4. Alakhfash AA, Tamimi Al, Khattabi AM, et al. Treatment options for transposition of the great arteries with ventricular septal defect complicated by pulmonary vascular obstructive disease. J Saudi Heart Assoc. 2009;21(3): 187-90.

5. Zartner PA, Schneider MB, Asfour B, et al. Enhanced left ventricular training in corrected transposition of the great arteries by increasing the preload. Eur J Cardiothorac Surg. 2016; 49(6): 1571-6.

6. Echocardiographic screeining of pulmonary hypertension in congenital hearth diseases. JACC journal.

7. Beghetti M, Schulze Neick I, Berger RM, et al. Haemodynamic characterisation and heart catheterisation complications in children with pulmonary hypertension: Insights from the Global TOPP Registry (tracking outcomes and practice in paediatric pulmonary hypertension). Int J Cardiol. 2016;203: 325-30.

8. Kirzner J, Pirmohamed A, Ginns J, et al. Long-term Management of the Arterial Switch Patient. Curr Cardiol Rep. 2018;20(8): 68.

9. Safi LM, Bhatt AB. Update on the Management of Adults With Arterial Switch Procedure for Transposition of the Great Arteries. Curr Treat Options Cardiovasc Med. 2017;19 (1): 4. 